\title{
Block Copolymer-Assisted Nanopatterning of Porous Lead Titanate Thin Films for Advanced Electronics
}

\author{
${\text { Alichandra } \text { Castro }^{1} \text {, Paula Ferreira }}^{1 *}$, Paula M. Vilarinho ${ }^{1 *}$ \\ ${ }^{1} \mathrm{CICECO}$ - Aveiro Materials Institute, Department of Materials and Ceramic \\ Engineering, University of Aveiro, 3810-193 Aveiro, Portugal
}

\section{Supporting Information}

To follow the complete PB- $b$-PEO decomposition and the phase formation, thermal gravimetric and differential thermal analyses (TGA-DTA) were carried out on dried powder of the deposition solution under flowing air up to $650^{\circ} \mathrm{C}$.

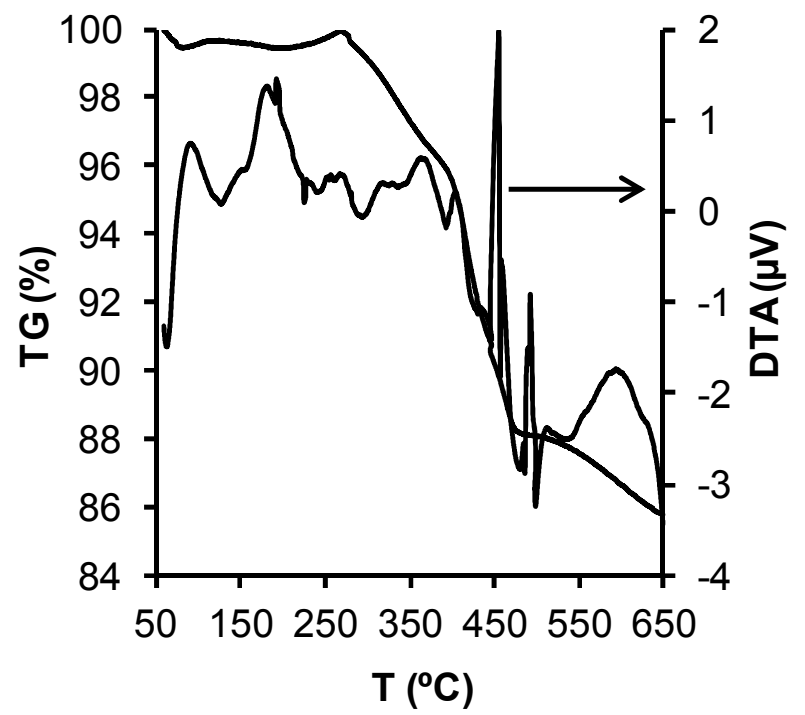

Figure S1: TGA-DTA of dried powders of the depotion solution used to prepare the nanopatterned $\mathrm{PbTiO}_{3}$ thin films. The TG curve presents a significant weight loss from 250 to $450{ }^{\circ} \mathrm{C}$. 
Figure S1 presents TGA-DTA analyses of dried powders of the deposition solution used to prepare nanopatterned thin films of $\mathrm{PbTiO}_{3}$. The TGA curve clearly show a significant weight loss (from 250 to $450{ }^{\circ} \mathrm{C}$ ) which is assigned to the decomposition of organics. From 450 to $650{ }^{\circ} \mathrm{C}$ the weight loss reaches a value of $3 \%$ attributed to the decomposition of residual species. DTA is characterized by several thermal effects. However, these thermal effects can be attributed to the decomposition of PEO (poly(ethylene oxide)) from 150 to $250{ }^{\circ} \mathrm{C}$ and to the decomposition of PB (Poly(butadiene)) from 250 to $450{ }^{\circ} \mathrm{C}$ which corresponds to the higher weight loss, around $10 \%$.

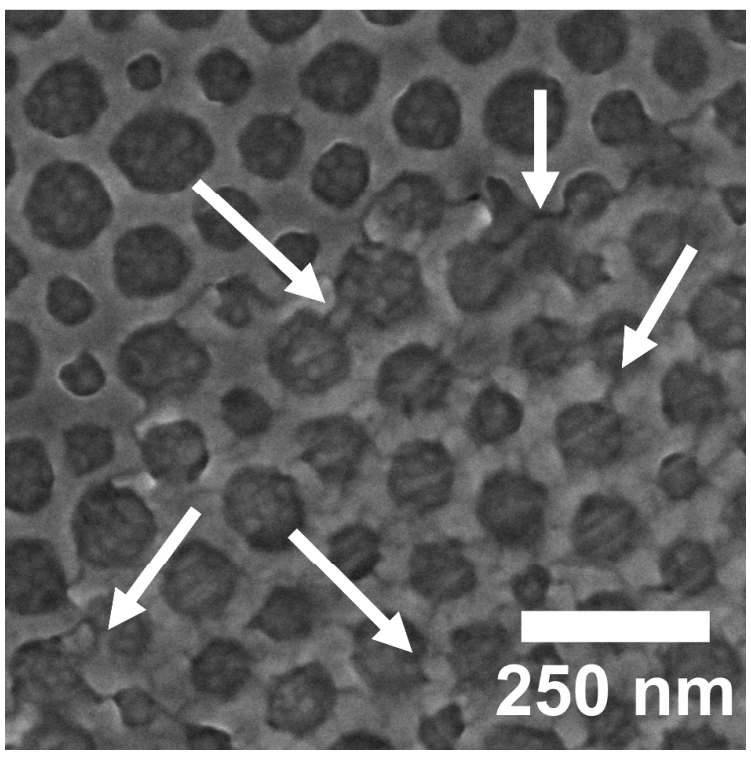

Figure S2. SEM micrograph of a thin film deposited with High $\mathrm{C}$ and $1.6 \mathrm{~mm} / \mathrm{s}$ withdrawal rate and treated at $650{ }^{\circ} \mathrm{C}$. The arrows indicate zones where the porous structure starts to collapse. 